\title{
KORELASI RERATA NILAI POSTTEST TERHADAP NILAI OBJECTIVE STRUCTURED PRACTICAL EXAMINATION (OSPE) ANATOMI DAN HISTOLOGI MAHASISWA KEDOKTERAN BLOK 1.1 FAKULTAS KEDOKTERAN DAN ILMU KESEHATAN UNIVERSITAS JAMBI TAHUN 2019
}

\author{
Rina Nofri Enis ${ }^{1}$, Intan Karnina Putri' ${ }^{2}$ Amelia Dwi Fitri ${ }^{3}$, Erny Kusdiyah ${ }^{3}$ \\ ${ }^{1}$ Bagian Anatomi Fakultas Kedokteran dan Ilmu Kesehatan Universitas Jambi \\ ${ }^{2}$ Mahasiswa Program Studi Kedokteran, Fakultas Kedokteran dan Ilmu \\ Kesehatan Universitas Jambi \\ ${ }^{3}$ Bagian Histologi Fakultas Kedokteran dan Ilmu Kesehatan Universitas Jambi
}

[email korespondensi: rinanofrienis@unja.ac.id]

\begin{abstract}
The Correlation Between Posttest Value and Objective Structured Practical Examination (OSPE) Value in Anatomy and Histology Subject for Medical Student Block 1.1 at Medical Faculty Universitas Jambi Year 2019. Curriculum development, strategies, and evaluation in medical education are embodied in the SPICES strategy. FKIK UNJA is applying this strategy in learning such as Anatomy and Histology. Evaluation system in FKIK UNJA including summative and formative assessments. Summative assessment consists of MCQ and OSPE which is give contribution about $80 \%$ for final grade and formative assessment which give contribution $20 \%$ such as pretest and posttest that held in anatomy and histology practice classes. Posttest was used to identify student's abilities after practiced in the lab. This research aims to determine the correlation average value of the posttest with OSPE Anatomy and Histology among student of block 1.1 FKIK UNJA 2019. This research is observational analytic study with cross sectional approach. The participants were first year medical student in block 1.1 FKIK UNJA. Pearson Correlation analysis showed statistically significant correlation between variable with the value of significance $p=0.000(p<0.05)$ between the mean value of posttest and anatomy and histology OSPE. While the strength of the correlation of mean value of anatomy posttest to anatomy OSPE in the strong category with the values $r=0.693$, while the strength of the correlation of mean value of histology posttest to histology OSPE in medium category with the value $r=0.414$. The results of the research showed that there was a statistically significant correlation between mean value of posttest and OSPE score for anatomy and histology.
\end{abstract}

Keywords: OSPE, Posttest, Evaluation Medical Education, Anatomy, Histology

\begin{abstract}
Abstrak: Korelasi Rerata Nilai Posttest Terhadap Nilai Objective Structured Practical Examination (Ospe) Anatomi Dan Histologi Mahasiswa Kedokteran Blok 1.1 Fakultas Kedokteran Dan Ilmu Kesehatan Universitas Jambi Tahun 2019. Perkembangan kurikulum, strategi, serta evaluasi pembelajaran dalam pendidikan kedokteran telah diaplikasikan melalui strategi SPICES. FKIK UNJA juga telah menerapkan strategi ini yang diantaranya terdiri atas ilmu anatomi dan histologi. Penerapan sistem evaluasi di FKIK UNJA diantaranya terdiri atas evaluasi sumatif dan formatif. Evaluasi sumatif terdiri atas MCQ dan OSPE sebesar maksimal 80\%, dan evaluasi formatif sebanyak $20 \%$ dengan diantaranya penilaian hasil pretest dan posttest. Posttest juga digunakan sebagai instrumen penilaian untuk mengenali kemampuan mahasiswa setelah mengikuti pembelajaran. Penelitian ini bertujuan untuk mengetahui korelasi rerata nilai posttest terhadap nilai OSPE anatomi dan
\end{abstract}


histologi mahasiswa blok 1.1 FKIK UNJA 2019. Studi ini merupakan studi analitik observasional dengan pendekatan cross sectional yang melibatkan seluruh mahasiswa blok 1.1 FKIK UNJA 2019 dengan kKriteria inklusi mahasiswa FKIK UNJA semester pertama yang mengikuti OSPE blok 1.1. Didapatkan total 108 mahasiswa pada anatomi dan 118 mahasiswa pada histologi yang diuji. Uji Korelasi Pearson memperlihatkan adanya korelasi kedua variabel dengan nilai signifikansi $p=0,000(p<0,05)$ antara rerata nilai posttest terhadap nilai OSPE anatomi. Sedangkan kekuatan derajat korelasi rerata nilai posttest terhadap nilai OSPE histologi dalam kategori kuat dengan nilai $r=0,693$, sedangkan kekuatan derajat korelasi rerata nilai posttest histologi terhadap nilai OSPE dalam kategori sedang dengan nilai $r=0,414$. Adanya hubungan positif bermakna antara rerata nilai posttest terhadap nilai OSPE anatomi dan histologi mahasiswa kedokteran blok 1.1.

Kata Kunci: OSPE, Posttest, Evaluasi Pendidikan Kedokteran, Anatomi, Histologi

\section{PENDAHULUAN}

Pada beberapa tahun terakhir, sejumlah ide dan kecenderungan baru dalam dunia pendidikan kedokteran mulai terlihat jelas. Beberapa hal yang terlihat berupa perkembangan kurikulum dan strategi, perhatian terhadap hasil pembelajaran, serta bagaimana cara melakukan penilaian untuk mencapai hasil pembelajaran (Dent, 2013).

Penerapan strategi / pendekatan model SPICES (Student centered, Problem-based, Integrated, Community -based, Elective or Early Clinical Exposure, Systematic) mewakili setiap strategi sebagai satu kesatuan dan menghindari opini yang bertentangan dalam penyelenggaraan pendidikan kedokteran (Dent, 2013). Pendekatan ini diharapkan dapat membentuk dokter yang memiliki kemampuan belajar mandiri, menyelesaikan masalah yang dihadapi, dan membentuk dokter yang sesuai dengan kebutuhan masyarakat (KKI, 2012). Konsil Kedokteran Indonesia (KKI) menyatakan bahwa model kurikulum bagi pendidikan kedokteran yang sesuai adalah Kurikulum Berbasis Kompetensi (KBK) dengan strategi SPICES (Akbar dkk, 2014). Struktur kurikulum terdiri dari tahap sarjana kedokteran dan tahap profesi (Harden, 2009).

Program Studi Kedokteran
Fakultas Kedokteran dan Ilmu

Kesehatan Universitas Jambi (FKIK UNJA) telah menerapkan Kurikulum Berbasis Kompetensi (KBK) sejak tahun 2007. Penerapan KBK dilakukan dengan memperhatikan prinsip metode ilmiah dan prinsip kurikulum spiral serta mengacu pada Standar Kompetensi Dokter Indonesia (FKIK UNJA, 2017). Anatomi dan Histologi termasuk kedalam cabang ilmu Kedokteran dasar. Proses pembelajaran yang dilakukan berupa perkuliahan dan disertai dengan kegiatan praktikum di laboratorium dengan bimbingan dosen (Böckers et al, 2010).

Praktikum anatomi di FKIK UNJA dimulai dengan pemberian pretest pada awal pertemuan, kemudian dilanjutkan dengan kuliah tatap muka berupa penyampaian materi melalui power point, media berupa preparat basah, mannequin (model) anatomi, tulang-tulang, gambar-gambar anatomi, dan buku atau atlas gross anatomi (Chabot, 2013). Pada akhir sesi praktikum, dilakukan pemberian posttest sebagai tolak ukur dari pemahaman mahasiswa selama mengikuti kegiatan pembelajaran praktikum (Sbayeh, 2016). Hal ini juga dilakukan pada kegiatan pembelajaran praktikum histologi, yang berbeda adalah setelah pemaparan materi oleh dosen, mahasiswa diberikan waktu untuk menggambarkan preparat yang telah diamati beserta keterangan-keterangan yang telah dipaparkan oleh dosen pembimbing 
(Musumeci, 2014). Setelah seluruh kegiatan praktikum anatomi maupun histologi diselesaikan dalam setiap blok, maka penilaian akhir berupa Objective Structured Practical Examination (OSPE) (Manjula, 2013); (Rehman et al, 2012).

Sistem Assesmen pada tahap sarjana kedokteran dilakukan melalui evaluasi pendidikan berdasarkan evaluasi formatif dan evaluasi sumatif pada tiap blok selama satu semester (Amin, 2009). Penilaian blok didasarkan pada evaluasi sumatif yang terdiri atas Ujian tulis berupa Multiple Choice Question (MCQ) dengan bobot sebesar $60 \%$ dari nilai akhir blok. Ujian praktikum ilmu Biomedik berupa OSPE memiliki bobot $20 \%$ serta evaluasi formatif memberikan kontribusi pada nilai akhir blok sebesar $20 \%$. Evaluasi formatif terdiri dari penilaian performa mahasiswa dalam tutorial dan skills lab sebesar $10 \%$, penilaian pretest dan posttest praktikum dalam bagian ilmu biomedik sebesar 5\% dan Assignment sebesar 5\% (FKIK UNJA, 2017).

Kelulusan dalam OSPE Anatomi dan Histologi menjadi pencapaian yang cukup besar karena akan mempengaruhi sebanyak $20 \%$ evaluasi formatif kelulusan Mahasiswa Kedokteran FKIK UNJA (FKIK UNJA, 2017). Pelaksanaan pretest dibutuhkan untuk membentuk prior knowledge sedangkan posttest diperlukan untuk mengukur pembelajaran yang telah dilakukan (Delucchi, 2014). Sehingga diharapkan pelaksanaan posttest pada praktikum anatomi dan histologi di Fakultas Kedokteran dan Ilmu Kesehatan Universitas Jambi mampu menjadi instrumen penilaian awal yang berguna bagi mahasiswa, dosen pembimbing, agar mampu mencapai standar kelulusan yang telah ditetapkan (Hasan, 2009); (Ronald, 1980). Hasil yang didapatkan pada nilai posttest dapat digunakan untuk mengenali kemampuan yang dimiliki setiap mahasiswa, serta dapat menjadi dokumentasi dari sistem pembelajaran yang telah berlangsung, sehingga saat tidak adanya value added dalam sebuah kelas, hal tersebut dapat menjadi indikasi dibutuhkannya perbaikan dalam perkuliahan (Delluci, 2014).

Hingga saat ini belum ada penelitian mengenai korelasi rerata nilai posttest praktikum anatomi dan histologi terhadap hasil OSPE anatomi dan histologi, maka peneliti tertarik untuk melakukan penelitian yang berjudul "Korelasi Rerata Nilai Posttest terhadap Nilai Objective Structured Practical Examination (OSPE) Anatomi dan Histologi Mahasiswa Kedokteran Blok 1.1 Fakultas Kedokteran dan IImu Kesehatan Universitas Jambi Tahun 2019."

\section{METODE}

Penelitian ini merupakan studi analitik observasional dengan pendekatan cross sectional. Populasi pada penelitian ini adalah semua mahasiswa kedokteran blok 1.1 angkatan 2019 FKIK UNJA. Sampel penelitian adalah seluruh populasi yang telah memenuhi kriteria inklusi dengan besar sampel minimal sebanyak 97 sampel.

Kriteria inklusi pada penelitian ini yaitu Mahasiswa kedokteran semester pertama FKIK UNJA yang mengikuti OSPE pada blok 1.1, dengan kriteria eksklusi adalah mahasiswa yang tidak mengikuti posttest anatomi dan histologi secara lengkap pada blok 1.1. Metode Pengumpulan data yang digunakan dalam penelitian adalah dokumentasi daftar nilai posttest praktikum anatomi dan histologi serta daftar nilai OSPE Anatomi dan Histologi mahasiswa blok 1.1. Analisis data yang digunakan dalam penelitian ini adalah univariat yaitu data disajikan dalam bentuk tabel dan narasi, selanjutnya analisis bivariat yang menggunakan uji statistik analisis korelasi Pearson untuk menguji korelasi dua variabel.

\section{HASIL}

\section{a. Gambaran Rerata Nilai Posttest Anatomi}

Dari table 1 diketahui gambaran rerata nilai posttest anatomi dari 108 mahasiswa blok 1.1 FKIK UNJA tahun 2019. Hasil analisis didapatkan 
frekuensi terbesar pada rerata nilai 80-100 dengan persentase 24\%, sedangkan frekuensi terkecil pada rerata nilai 60-61,99 dengan persentase $4,6 \%$. Selanjutnya pada table 2 diketahui rerata nilai terbesar yaitu 97 dan rerata nilai terkecil yaitu
27 dengan nilai mean yang didapatkan sebesar 68,79 serta nilai range dan median sebesar 70 .

Tabel 1. Rerata nilai posttest anatomi mahasiswa blok 1.1

\begin{tabular}{clcc}
\hline \multirow{2}{*}{ Rerata Nilai Posttest } & \multirow{2}{*}{ Huruf Mutu } & \multicolumn{2}{c}{ Mahasiswa } \\
\cline { 3 - 4 } & A & Frekuensi & \% \\
\hline $80-100$ & A- & 7 & $24 \%$ \\
$77-79$ & B & 8 & $6,40 \%$ \\
$75-76,99$ & B & 14 & $7,40 \%$ \\
$70-74,99$ & B- & 10 & $12,90 \%$ \\
$67-69,99$ & C & 13 & $9,25 \%$ \\
$62-66,99$ & C & 5 & $12 \%$ \\
$60-61,99$ & D+ & 8 & $4,60 \%$ \\
$55-59,99$ & D & 7 & $7,40 \%$ \\
$45-54,99$ & E & 10 & $6,40 \%$ \\
$\leq 44,99$ & Jumlah & 108 & $9,25 \%$ \\
\hline
\end{tabular}

Tabel 2. Distribusi rerata nilai posttest anatomi mahasiswa blok 1.1

\begin{tabular}{cccccc}
\hline Variabel & Mean & Minimum & Maximum & Range & Median \\
\hline $\begin{array}{c}\text { Rerata nilai } \\
\text { posttest anatomi }\end{array}$ & 68,79 & 27 & 97 & 70 & 70 \\
\hline
\end{tabular}

\section{b. Gambaran Rerata Nilai Posttest} Histologi

Dari tabel 3 diketahui gambaran rerata nilai posttest histologi dari 118 mahasiswa blok 1.1 FKIK UNJA tahun 2019. Hasil analisis didapatkan frekuensi terbesar pada rerata nilai 62-66,99 dengan persentase 18,64\%, sedangkan frekuensi terkecil pada interval nilai 60-61,99 dan 77-79 dengan masing-masing persentase $3,39 \%$. Selanjutnya pada table 4 diketahui rerata nilai terbesar yaitu 85 dan rerata nilai terkecil yaitu 32 dengan nilai mean yang didapatkan sebesar 63,42 serta nilai range sebesar 53 dan median sebesar 70 .

Tabel 3. Rerata nilai posttest histologi mahasiswa blok 1.1

\begin{tabular}{cccc}
\hline \multirow{2}{*}{ Rerata Nilai Posttest } & Huruf & \multicolumn{2}{c}{ Mahasiswa } \\
\cline { 3 - 4 } & Mutu & Frekuensi & \% \\
\hline $80-100$ & $\mathrm{~A}$ & 8 & $6,78 \%$ \\
$77-79$ & $\mathrm{~A}-$ & 4 & $3,39 \%$ \\
$75-76,99$ & $\mathrm{~B}+$ & 5 & $4,23 \%$ \\
$70-74,99$ & $\mathrm{~B}$ & 21 & $17,80 \%$ \\
$67-69,99$ & $\mathrm{~B}-$ & 15 & $12,71 \%$ \\
$62-66,99$ & $\mathrm{C}+$ & 22 & $18,64 \%$ \\
$60-61,99$ & $\mathrm{C}$ & 4 & $3,39 \%$ \\
$55-59,99$ & $\mathrm{D}+$ & 16 & $13,56 \%$ \\
$45-54,99$ & $\mathrm{D}$ & 16 & $13,56 \%$ \\
$\leq 44,99$ & $\mathrm{E}$ & 7 & $5,93 \%$ \\
\hline
\end{tabular}


Tabel 4. Distribusi rerata nilai posttest histologi mahasiswa blok 1.1

\begin{tabular}{cccccc}
\hline Variabel & Mean & Minimum & Maximum & Range & Median \\
\hline $\begin{array}{c}\text { Rerata nilai } \\
\text { posttest histologi }\end{array}$ & 63,42 & 32 & 85 & 53 & 65 \\
\hline
\end{tabular}

\section{c. Gambaran nilai OSPE Anatomi}

Dari tabel 5 diketahui gambaran nilai OSPE anatomi dari 108 mahasiswa blok 1.1 FKIK UNJA tahun 2019. Hasil analisis memperlihatkan frekuensi terbesar pada nilai 45-54,99 dan $\leq 44,99$ dengan masing-masing persentase $25 \%$, sedangkan frekuensi terkecil pada nilai 75-76,99 dengan persentase $0 \%$. Selanjutnya pada tabel 6 diketahui nilai terbesar yaitu 86 dan nilai terkecil yaitu 17 dengan nilai mean yang didapatkan sebesar 54,53 serta nilai range sebesar 69 dan median sebesar 55 .

Tabel 5. Rerata nilai OSPE anatomi mahasiswa blok 1.1

\begin{tabular}{cccc}
\hline \multirow{2}{*}{ Rerata Nilai Posttest } & Huruf & \multicolumn{2}{c}{ Mahasiswa } \\
\cline { 3 - 4 } & Mutu & Frekuensi & \% \\
\hline $80-100$ & $\mathrm{~A}$ & 3 & $2,78 \%$ \\
$77-79$ & $\mathrm{~A}-$ & 5 & $4,62 \%$ \\
$75-76,99$ & $\mathrm{~B}+$ & 0 & 0 \\
$70-74,99$ & $\mathrm{~B}$ & 10 & $9,25 \%$ \\
$67-69,99$ & $\mathrm{~B}-$ & 5 & $4,62 \%$ \\
$62-66,99$ & $\mathrm{C}+$ & 13 & $12,03 \%$ \\
$60-61,99$ & $\mathrm{C}$ & 10 & $9,25 \%$ \\
$55-59,99$ & $\mathrm{D}+$ & 8 & $7,40 \%$ \\
$45-54,99$ & $\mathrm{D}$ & 27 & $25 \%$ \\
$\leq 44,99$ & $\mathrm{E}$ & 27 & $25 \%$ \\
\hline Jumlah & & 108 & $100 \%$ \\
\hline
\end{tabular}

Tabel 6. Distribusi rerata nilai OSPE anatomi mahasiswa blok 1.1

\begin{tabular}{ccccccc}
\hline Variabel & Mean & Minimum & Maximum & Range & Median \\
\hline Nilai OSPE anatomi & 54,53 & 17 & 86 & 69 & 55 \\
\hline
\end{tabular}

d. Gambaran nilai OSPE histologi

Dari table 7 diketahui gambaran nilai OSPE histologi dari 118 mahasiswa blok 1.1 FKIK UNJA tahun 2019. Hasil analisis didapatkan frekuensi terbesar berada pada nilai $\leq 44,99$ dengan persentase $36,44 \%$. Sedangkan frekuensi terkecil berada pada nilai
75-76,99 dan 55-59,99 dengan masing-masing persentase $0 \%$. Selanjutnya pada table 8 diketahui nilai terbesar yaitu 88 dan nilai terkecil yaitu 10 dengan nilai mean yang didapatkan sebesar 49,49 serta nilai range sebesar 78 dan median sebesar 49.

Tabel 7. Nilai OSPE histologi mahasiswa blok 1.1

\begin{tabular}{cccc}
\hline \multirow{2}{*}{ Rerata Nilai Posttest } & Huruf & \multicolumn{2}{c}{ Mahasiswa } \\
\cline { 3 - 4 } & Mutu & Frekuensi & \% \\
\hline $80-100$ & A & 5 & $4,24 \%$ \\
$77-79$ & A- & 4 & $3,39 \%$ \\
$75-76,99$ & B & 0 & 0
\end{tabular}




\begin{tabular}{|c|c|c|c|c|c|}
\hline $70-74,99$ & B & & 12 & \multicolumn{2}{|c|}{$10,17 \%$} \\
\hline $67-69,99$ & B- & & 8 & \multicolumn{2}{|c|}{$6,78 \%$} \\
\hline $62-66,99$ & $C+$ & & 9 & \multicolumn{2}{|c|}{$7,62 \%$} \\
\hline $60-61,99$ & C & & 6 & \multicolumn{2}{|c|}{$5,08 \%$} \\
\hline $55-59,99$ & $D+$ & & 0 & \multicolumn{2}{|c|}{0} \\
\hline $45-54,99$ & $\mathrm{D}$ & & 31 & \multicolumn{2}{|c|}{$26,27 \%$} \\
\hline$\leq 44,99$ & E & & 43 & \multicolumn{2}{|c|}{$36,44 \%$} \\
\hline \multicolumn{2}{|l|}{ Jumlah } & & 118 & \multicolumn{2}{|c|}{$100 \%$} \\
\hline \multicolumn{6}{|c|}{ Table 8. Distribusi rerata nilai OSPE histologi mahasiswa blok 1.1 } \\
\hline Variabel & Mean & Minimum & Maximum & Range & Median \\
\hline Nilai OSPE histologi & 49,49 & 10 & 88 & 78 & 49 \\
\hline
\end{tabular}

\section{Korelasi Rerata Nilai Posttest terhadap Nilai OSPE}

Tabel 9 menunjukkan hasil uji hipotesis yang dilakukan menggunakan Uji Korelasi Pearson ditemukan korelasi bermakna $p=0,000 \quad(p<0,05)$ antara rerata nilai posttest anatomi terhadap nilai OSPE anatomi. Selanjutnya nilai pearson correlation memperlihatkan derajat korelasi positif dalam kategori kuat antara kedua variabel dengan nilai $r=0,693$. Sedangkan dari hasil uji hipotesis yang dilakukan menggunakan Uji Korelasi Pearson ditemukan korelasi bermakna $p=0,000 \quad(p<0,05)$ antara rerata nilai posttest histologi terhadap nilai OSPE histologi. Selanjutnya nilai pearson correlation memperlihatkan derajat korelasi positif dalam kategori sedang antara kedua variabel dengan nilai $r=0,414$.

\begin{tabular}{lc}
$\begin{array}{l}\text { Tabel 9. Korelasi rerata nilai Posttest terhadap nilai OSPE anatomi da } \\
\text { histologi }\end{array}$ \\
\hline Rerata Nilai Posttest Anatomi terhadap Nilai OSPE Anatomi \\
$\begin{array}{c}\mathrm{p}=0.000 \\
\mathrm{r}=0.693 \\
\mathrm{n}=108\end{array}$ \\
$\mathrm{p}=0.000$ \\
$\mathrm{r}=0.414$ \\
$\mathrm{n}=118$ \\
\hline
\end{tabular}

\section{PEMBAHASAN}

Berdasarkan hasil penelitian didapatkan kesesuaian terhadap hipotesis berupa adanya korelasi bermakna antara rerata nilai posttest terhadap nilai OSPE anatomi dan histologi pada mahasiswa kedokteran blok 1.1 Fakultas Kedokteran dan Ilmu Kesehatan Universitas Jambi tahun 2019. Dari hasil analisis bivariat didapatkan korelasi rerata nilai posttest anatomi terhadap nilai OSPE anatomi dengan kategori kuat, sedangkan korelasi rerata nilai posttest histologi terhadap nilai OSPE histologi berada dalam korelasi kategori sedang. Hal ini berarti menjelaskan bahwa semakin besar rerata nilai posttest yang diperoleh mahasiswa maka semakin besar pula nilai OSPE yang didapat oleh mahasiswa.

Posttest sebagai salah satu bentuk tes formatif dan OSPE sebagai hasil akhir dari pembelajaran dan merupakan salah satu bentuk dari tes sumatif (Khafid, 2015). Dari hasil penelitian ini dan penelitian-penelitian sebelumnya menemukan bahwa bentuk tes formatif memiliki korelasi yang positif terhadap hasil pembelajaran yang diperoleh dan dapat digunakan sebagai prediktor dari hasil pembelajaran sumatif pada siswa (Yuningsih, 2013).

Sesuai dengan penelitian Mitra dan Barua juga menemukan hubungan 
antara hasil tes formatif berbasis komputer terhadap peningkatan hasil tes sumatif mahasiswa kedokteran pada pembelajaran muskuloskeletal (Mitra \& Barua, 2015). Kemudian pada penelitian Krasne et al, menyimpulkan bahwa hasil tes formatif dapat digunakan sebagai alat prediksi yang efektif terhadap hasil sumatif mahasiswa semester pertama di pendidikan kedokteran (Krasne et al, 2006).

Pada hasil penelitian ini ditemukan perbedaan kekuatan korelasi antara rerata nilai posttest anatomi terhadap nilai OSPE anatomi dengan rerata nilai posttest histologi terhadap nilai OSPE histologi. Korelasi pada rerata nilai posttest memiliki koefisien korelasi yang sedikit lebih besar terhadap nilai OSPE anatomi jika dibandingkan dengan koefisien korelasi rerata nilai posttest histologi terhadap nilai OSPE histologi. Yaitu kategori kuat pada korelasi antara rerata nilai posttest terhadap nilai OSPE anatomi dan kategori sedang pada korelasi rerata nilai posttest terhadap nilai OSPE histologi.

Hasil penelitian ini juga memperlihatkan bahwa persentase kelulusan $\geq 60$ pada hasil posttest dan OSPE memiliki perbedaan yang signifikan. Pada tabel rerata nilai posttest anatomi didapatkan sebanyak $46,5 \%$ mahasiswa yang mendapatkan nilai $\geq 60$, sedangkan pada nilai OSPE anatomi sebanyak $42,55 \%$ mahasiswa. Selanjutnya antara hasil posttest dan OSPE histologi memiliki perbedaan yang sangat signifikan. Didapatkan $66,94 \%$ mahasiswa yang mendapatkan nilai $\geq 60$ pada posttest histologi, sedangkan pada OSPE histologi hanya didapatkan $37,28 \%$ mahasiswa yang mendapatkan nilai $\geq 60$. Hal ini memperlihatkan adanya perbedaan dalam aspek evaluasi antara tes formatif dan juga tes sumatif.

\section{KESIMPULAN}

Rerata nilai posttest anatomi pada mahasiswa kedokteran blok 1.1 adalah nilai rerata terbesar 97 dengan nilai rerata terkecil 27 dan nilai mean sebesar 68,79. Sedangkan rerata nilai posttest histologi pada mahasiswa kedokteran blok 1.1 yaitu rerata nilai terbesar 85 dengan rerata nilai terkecil 32 dan nilai mean sebesar 63,42.

$$
\text { Nilai OSPE anatomi pada }
$$

mahasiswa kedokteran blok 1.1 memiliki nilai terbesar 86 dan nilai terkecil 17, serta nilai mean sebesar 54,53. Sedangkan nilai OSPE histologi pada mahasiswa kedokteran blok 1.1 memiliki nilai terbesar 88 dan nilai terkecil yaitu 10, serta nilai mean sebesar 49,49.

Pada hasil penelitian ditemukan korelasi positif bermakna dengan kategori kuat antara rerata nilai posttest anatomi terhadap nilai OSPE anatomi mahasiswa kedokteran blok 1.1. serta adanya korelasi positif bermakna dengan kategori sedang antara rerata nilai posttest histologi terhadap nilai OSPE histologi mahasiswa kedokteran blok 1.1 dengan rerata nilai posttest dan OSPE anatomi lebih tinggi dibandingkan rerata nilai posttest dan OSPE histologi.

\section{SARAN}

Untuk proses pembelajaran di FKIK UNJA diharapkan dapat meningkatkan kualitas belajar mengajar terutama dalam pembelajaran anatomi dan histologi baik dari sisi sarana prasarana, kebutuhan praktikum, perkuliahan, tenaga pengajar, jadwal perkuliahan, dan juga kurikulum yang bersangkutan agar tercipta kegiatan belajar mengajar yang berkualitas yang diharapkan dalam jangka panjang akan berdampak terhadap peningkatan keterampilan, penguasaan, serta pemahaman setiap mahasiswa tingkat pertama terhadap Ilmu Anatomi dan Histologi.

\section{DAFTAR PUSTAKA}

Akbar S, Claramita M, Kristina $T$. (2014). Pengembangan Kuisioner Penilaian Proses Belajar Problem-Based Learning 
dengan Model Spices. Jurnal AIPKI. 3: 137-44.

Amin Z, Eng KH. (2009). Basics in Medical Education, Singapura. World Scientific: 20.

Amin Z, Eng KH. (2009). Basics in medical Education. Singapura. World Scientific: 239-30.

Arráez-Aybar. (2010). Relevance of human anatomy in daily clinical practice. Annals of Anatomy. 192: 341-348.

Azer S. (2008). Navigating Problem Based Learning. Sydney. Churchill Livingston Elsevier: 165-72

Böckers, A, Jerg-Bretzke, L, Lamp, C, Brinkmann, A, Traue, HC, Böckers, TM. (2010). The gross anatomy course: an analysis of its importance. Anat Sci Educ. 3: 3-11.

Chabot, Costa M, Chaffey, Cabrillo. (2013). Pre-and Post-Test Information. Boston University. Colleges SLO websites.

Delucchi M. (2014). Measuring Student Learning in Social Statistics: A Pretest-Postest Study of Knowledge Gain. ASA (serial online), 42(3): 231-239. DOI: $10.1177 / 0092055 \times 14527909$.

Dent JA, Harden RM. (2013). A Practical Guide for Medical Teachers. Fourth Edition. Philadelphia. Churchill Livingston Elsevier: 5.

Dent JA, Harden RM. (2013). A Practical Guide for Medical Teachers. Fourth Edition. Philadelphia. Churchill Livingston Elsevier: 400-401.

Dent JA, Harden RM. (2013). A Practical Guide for Medical Teachers. Fourth Edition. Philadelphia. Churchill Livingston Elsevier: 10.

FKIK UNJA. (2017). Peraturan Akademik Fakultas Kedokteran dan Ilmu Kesehatan Universitas Jambi tahun 2016/2017.

Harden RM, Dent JA. (2009). A Practical Guide Medical teacher. Philadelphia. Churchill Livingston Elsevier: 73-102.

Hasan S, Malik S, Hamad A, Khan $\mathrm{H}$, Bilal M. (2009). Conventional/
Traditional Practical Examintaion (CPE/TDPE) Versus Objective Structured Practical Evaluation (OSPE). Pak J Physiol (serial online): 5(1).

Hussein IH, Raad M, Safa R, Jurjus R. (2015). A Once Upon a Microscopic Slide: The Story of Histology. J Cytol Histol. (6): 377.

DOI:

10.4172/21577099.1000377.

Khafid M. (2014). Pengaruh pemberian tes formatif terhadap peningkatan hasil belajar pendidikan kesehatan pada siswa kelas VII SMP Negeri 2 Krian. Jurnal Pendidikan Olahraga dan Kesehatan. 02(01): 119-124.

Konsil Kedokteran Indonesia. (2012). Standar Pendidikan Profesi Dokter Indonesia. Jakarta. KKI: 1- 6.

Konsil Kedokteran Indonesia. (2012). Standar Pendidikan Profesi Dokter Indonesia. Jakarta. KKI: 18-21.

Krasne S, Wimmers P, Anju R, Drake AT. (2006). Differential Effects of Two Types of Formative Assesment in Predicting Performance of First-Year Medical Students. Advances in Health Sciences Education, 11: 155-171. 10.1007/s10459-005-5290-9

Manjula A, Shashikala P, Nagaraj P. (2013). Student's Perception on Objective Structured Practical Examination in Pathology. J Med Education \& Res 1(1): 12-14.

Mitra NK, Barua A. (2015). Effect of online formative assessment on summative performance in integrated musculoskeletal system module. BMC Medical Education: 29(15). DOI: 10.1186/s12909-015-0318

Musumeci G. (2014). Past, present and future: overview on histology and histopathology. Journal of Histology \& Histopathology (1): 5.

Rehman R, Syed S, Iqbal A, Rehan R. (2012). Perception and 
Performance of Medical Students in Objective Structured Practical Examination and Viva Voce. Pak J Physiol. 8(2): 33-36.

Ronald M, Harden, Robert G. (1980). Assessment of practical skills: The objective structured practical examination (OSPE). (diakses 11 April 2019); 5:(2), 187-196 Studies in Higher Education.

DOI: $10.1080 / 030750780123313$ 77216.

Sbayeh A. (2016). Relevance of anatomy to medical education and clinical practice: perspective of medical students, clinicians, and educators. Perspect Med Educ. 5: 338-346. DOI: 10.1007/ s40037-016-0310-4

Yuningsih S. (2013). Korelasi tes formatif dengan hasil belajar siswa pembelajaran matematika SDN 06 Mempawah Hilir. Pontianak: Fakultas Keguruan dan Ilmu Pendidikan Universitas Tanjung-pura. 